\title{
Case Study of an Epidemiological Approach Dissecting Historical Soybean Sclerotinia Stem Rot Observations and Identifying Environmental Predictors of Epidemics and Yield Loss
}

\author{
Mamadou L. Fall, John F. Boyse, Dechun Wang, Jaime F. Willbur, Damon L. Smith, and Martin I. Chilvers ${ }^{\dagger}$
}

First, second, third, and sixth authors: Department of Plant, Soil and Microbial Sciences, Michigan State University, East Lansing; and fourth and fifth authors: Department of Plant Pathology, University of Wisconsin-Madison, Madison.

Current address of M. L. Fall: Saint-Jean-sur-Richelieu Research and Development Centre, Agriculture and Agri-Food Canada, Saint-Jean-surRichelieu, QC, Canada.

Accepted for publication 3 December 2017.

\begin{abstract}
Sclerotinia sclerotiorum is a significant threat to soybean production worldwide. In this study, an epidemiological approach was used to examine 11 years of historical data from a soybean management performance trial in order to advance our understanding of Sclerotinia stem rot (SSR) development and to identify environmental predictors of SSR epidemics and associated yield losses. Recursive partitioning analysis suggested that average air temperature and total precipitation in July were the most significant variables associated with disease severity. High levels of SSR disease severity index were observed when the average temperature in July was below $19.5^{\circ} \mathrm{C}$ and total precipitation in July was moderate, between 20 and $108.5 \mathrm{~mm}$. A biphasic sigmoidal curve accurately described the relationship between SSR disease severity index (DSI) and yield, with a

DSI threshold of 22, below which minimal yield loss was observed. A $10 \%$ increase in the DSI, from 22.0 to 24.2 , led to an $11 \%$ decrease in yield, from $3,308.14$ to $2,951.29 \mathrm{~kg} / \mathrm{ha}$. Also, a yield threshold $(3,353 \mathrm{~kg} / \mathrm{ha})$ that was higher than the annual U.S. average soybean yield $(3,039.7 \mathrm{~kg} / \mathrm{ha})$ was suggested as an expected yield under low or no SSR pressure in the U.S. Midwest. These thresholds can allow soybean stakeholders to assess the value of disease control and establish an SSR baseline for cost-effective management to protect yields. Because $S$. sclerotiorum has more than 400 plant host species, and because having quantitative information concerning crop losses is crucial for decision making, this study shows the usefulness of historical data on SSR and, hence, can serve as a model in other SSR pathosystems (canola, dry bean, potato, pea, and so on).
\end{abstract}

Sclerotinia stem rot (SSR), caused by the fungus Sclerotinia sclerotiorum (Lib.) de Bary, is a major threat to many crops worldwide (Bolton et al. 2006; Saharan and Mehta 2008). The host range of $S$. sclerotiorum is very broad ( $>400$ plant species) and includes many important crops (soybean, potato, canola, tomato, pepper, dry bean, snap bean, pea, lettuce, tobacco, sunflower, and so on) and many important weeds of cultivated crops (mustard, nightshade, pigweed, Canada thistle, and so on) (Saharan and Mehta $2008)$. Since the pioneering work of de Bary $(1886,1887)$, the infection processes of $S$. sclerotiorum have been studied in several different host species, including bean (Abawi and Grogan 1975; Lumsden and Wergin 1980), lettuce (Purdy 1958; Tariq and Jeffries 1984), potato (Jones 1976), tomato (Purdy and Bardin 1953), sunflower (Sedun and Brown 1987), canola (Garg et al. 2010), and soybean (Sutton and Deverall 1983). In the United States, the disease was considered sporadic but has become an endemic threat to soybean production, especially in temperate locations (Wilson 2012). In soybean, SSR varies in incidence and severity from year to year,

${ }^{\dagger}$ Corresponding author: M. I. Chilvers; E-mail: chilvers@msu.edu

Funding: Funding for this study was provided, in part, by the Michigan Soybean Promotion Committee, the North Central Soybean Research Program, DuPont Crop Protection, and by United States Department of Agriculture-Agricultural Research Service Specific Cooperative Agreement number 58-5442-4-017 (National Sclerotinia Initiative).

*The $\boldsymbol{e}$-Xtra logo stands for "electronic extra" and indicates that two supplementary figures are published online.

This article is in the public domain and not copyrightable. It may be freely reprinted with customary crediting of the source. The American Phytopathological Society, 2018. because the pathogen and subsequent disease is heavily influenced by weather conditions (Peltier et al. 2012). Even though considerable efforts have been made to develop SSR-resistant soybean, no varieties are completely resistant. Partially resistant varieties are available and have significantly less disease than susceptible varieties (Peltier et al. 2012). Regardless of cultivar susceptibility, SSR is present when inoculum is present and weather conditions are conducive (Peltier et al. 2012).

The epidemiological process leading to SSR can be divided into three distinct stages: carpogenic germination of sclerotia, production and release of ascospores, and infection of the plant by ascospores. During the first stage, overwintered sclerotia germinate to produce one or multiple apothecia, each containing up to $2 \times 10^{6}$ ascospores (Adams and Ayers 1979; Schwartz and Steadman 1978). Moist soils and cool temperatures (between 16 and $20^{\circ} \mathrm{C}$ ) favor germination of sclerotia, which must be within the top $5 \mathrm{~cm}$ of the soil to form apothecia on the soil surface (Adams and Ayers 1979; Clarkson et al. 2014; Wu and Subbarao 2008). During the second stage, ascospores are forcefully discharged from the asci in the apothecia and aerially dispersed within the canopy and on air currents. Ascospores are considered to be the primary inoculum source for the majority of crops, including soybean (Abawi and Grogan 1975; Boland and Hall 1988; Calvin et al. 1972; Hartill 1980). Additionally, ascospore production and release have been demonstrated to coincide with flowering in crops such as potato and canola (Wale et al. 2008). During the third stage, viable ascospores that have been deposited on flowers germinate and colonize the flower petals prior to infecting the plant, which typically occurs at the nodes. Symptoms can be visible early on, depending on host susceptibility and weather conditions (Saharan and Mehta 2008). In addition, plants can be infected by contact with other diseased plants, often resulting in the spread of disease along the row (Hartman et al. 2015). 
SSR can considerably reduce yield, especially under weather conditions favorable for disease (Aldrich-Wolfe et al. 2015; Bolton et al. 2006; Peltier et al. 2012). Yield losses in the production of dry bean and snap bean in the United States were previously reported to be \$26 million and \$13 million, respectively (Fernando et al. 2004). Sunflower producers in the United States reportedly lose $\$ 15$ million annually owing to $S$. sclerotiorum (Fernando et al. 2004). In soybean, estimated yield losses in the United States from 1996 through 2009 due to SSR were more than 270 million $\mathrm{kg}$ in 7 of those 14 years (Koenning and Wrather 2010; Wrather and Koenning 2009). In 2004, 2009, and 2014, large soybean yield losses occurred in the U.S. Midwest as a result of SSR epidemics (Peltier et al. 2012; Wrather and Koenning, 2014). Those years were characterized by devastating SSR outbreaks (Wrather and Koenning 2014), presumably because of the below-average temperature and the amount of precipitation during flowering in July. Infection by S. sclerotiorum is favored by low to moderate daily temperature and moisture from rain, fog, dew, or high relative humidity (Workneh and Yang 2000). Field observations suggest that SSR can play a major role in soybean yield losses, especially in years with substantial precipitation and low temperatures during flowering, a critical period for SSR. Consequently, there is a need to determine the relationship between SSR and weather variables in order to improve our understanding of outbreak dynamics. However, soybean yield loss can be explained by many factors, including variety selection, planting date, and other major soybean diseases such as seedling disease, sudden death syndrome, and soybean cyst nematode (Koenning and Wrather 2010). The occurrence of SSR is often difficult to predict, and there is spatial variability in disease severity within and between fields. Thus, it has been a challenge to assess the impact of seasonal weather and the influence of cultivar on SSR and associated yield loss. Additionally, symptoms of SSR are usually not noticed until August, which is after the critical period for plant infection via flowers, which occurs in July. Therefore, some major epidemiological questions have arisen from these observations. What is the relationship between SSR severity and yield loss? Can weather parameters during the period around flowering be used to predict disease severity and subsequent yield loss?

The aims of this study were to answer these questions based on 11 years of historical data on SSR of soybean. Specifically, the study objectives were to (i) assess soybean cultivar maturity groups and soybean yield using 11 years of SSR data, (ii) determine the relationship between SSR severity and selected weather variables (average air temperature, maximum and minimum temperature, and precipitation), (iii) determine the relationship between SSR and yield loss, and (iv) define the influence of selected weather variables on this relationship. Therefore, this study involved a series of analyses to test the following hypotheses: (i) soybean yield will differ by maturity group and variety under overall SSR pressure, (ii) the SSR disease severity level is significantly correlated with some weather variables, (iii) a damage boundary for SSR that predicts measurable yield loss can be identified, and (iv) average air temperature and total precipitation in July significantly influence SSR severity and subsequent yield loss.

\section{MATERIALS AND METHODS}

Data collection. The experiments were conducted between 31 May and 30 October from 2000 through 2009 and in 2014. No data on SSR were recorded from 2010 to 2013. Each year, soybean was planted at Gerstenberger Farms (Salinac County, MI; latitude $43^{\circ} 25^{\prime}$, longitude $82^{\circ} 49^{\prime}$ ) in six-row plots, $6.10 \mathrm{~m}$ long with $0.38 \mathrm{~m}$ row spacing, at a seeding depth of $0.04 \mathrm{~m}$. The planting rate was 395,369 seeds/ha. At each location, varieties were replicated four times in a rectangular lattice design. SSR levels were determined by rating 30 consecutive plants in the center rows of each plot. Each plant was rated on a scale of 0 to 3 , as follows: $0=$ no infection, $1=$ infection on branches only, 2 = infection on the main stem but with normal pod fill, and $3=$ infection on the main stem that resulted in plant death and poor pod fill (Grau et al. 1982). The scores of the 30 plants rated for each plot were totaled. The total was divided by 90 (the total if all 30 scored plants had been given a rating of 3) and multiplied by 100 to give a disease severity index (DSI). Data were collected each year on 4 to 17 varieties encompassing 18 maturity groups from maturity groups 1.4 to 3.1 by 0.1 increments. Varieties were considered for analysis if they had been repeated in at least four different years. All plots were trimmed to a length of $4.28 \mathrm{~m}$, and the center four rows of each six-row plot were harvested using an Almaco four-row combine equipped with weigh buckets and a HarvestMaster system (Juniper Systems, Logan, UT). Harvest mass and moisture were determined. Grain yield (kilograms per hectare) was adjusted to $13 \%$ moisture.

Measurement of weather variables. The selection of variables was based on a preliminary analysis and the findings of previous studies (Mila et al. 2003, 2004). Soybean plants typically initiate flowering during July in the northern Midwest. An initial analysis and data observations showed that July was the most influential month in terms of disease development in comparison with August or a July-to-August window (data not shown). Thus, for each year, weather data for July and for July to September were used in the analysis. The latter period encompasses flowering through to crop maturity and disease cessation (growth stages R1 to R8). Variables included the average air temperature in July (Tp.J), average air temperature from 1 July to 30 September (Tp.JS), total precipitation in July (PP.J), average total precipitation from 1 July to 30 September (PP.JS), maximum temperature in July (Max.Tp.J), and minimum temperature in July (Min.Tp.J), which were obtained from the PRISM Climate Group website (Oregon State University; http:// prism.oregonstate.edu). More information about the descriptions of weather variables can be found on that website.

Data analysis. DSI and yield values (kilograms per hectare) were obtained as averages for each variety and each year, and normality of the data was tested using the Shapiro-Wilk test. All statistical tests were performed in R software, version 3.2.3 (https:// www.r-project.org/), as described below.

Yield performance of maturity groups and varieties under SSR disease pressure. Maturity groups. Data on yield and SSR severity were assessed by 0.1 maturity group increments. Graphical representations of yield and DSI as a function of maturity group were prepared using the easyGgplot2 and ggplot2 packages. An analysis of variance was used to investigate significant differences across years in yield and DSI among maturity groups (factor), and means across the yields and DSI among maturity groups were compared, using the Tukey honestly significant difference post hoc comparison. Only maturity groups that had been repeated in all years were considered.

Varieties. Generalized linear model analysis (nlme package) was performed to detect significant differences in yield among varieties. Because the number of years that each variety was repeated during the 11 years (unbalanced design) and disease severity among years were different, the independent variables (DSI, variety, and year) were entered in different orders to see how much of a difference this would make to the outcomes of the analysis (agricolae package: Statistical Procedures for Agricultural Research, version 1.1.4). When the full model was statistically significant $(\alpha=0.05)$, mean yields among varieties were compared, and a pairwise $t$ test was used to calculate the adjusted $P$ values (agricolae: Statistical Procedures for Agricultural Research) (Logan 2010). To avoid introducing bias for the subsequent analyses, only varieties expressing no statistical difference with respect to yield were considered for the other analyses; hence, one variety (Vinton 81) was removed.

Relationship between soybean SSR severity and selected weather variables. Correlations among SSR severity, yield, and weather variables were analyzed using Pearson's correlation matrix in $\mathrm{R}$ (Hmisc package). Temperature and precipitation were selected to define the relationship between SSR and weather variables, because favorable temperature and precipitation conditions promote 
SSR development (Workneh and Yang 2000). The selected weather variables were Tp.J, Tp.JS, PP.J, PP.JS, Max.Tp.J, and Min.Tp.J. A scatter plot representing the DSI as a function of PP.J was prepared for the data from all 11 years. To describe the relationship, a threeparameter peak lognormal model was fitted to the scatter plot as follows:

$$
y=\frac{a}{x} * \exp \left[-0.5\left(\frac{\ln \left(x / x_{0}\right)}{b}\right)^{2}\right]
$$

where $y$ is the DSI, $a / x$ sets the amplitude of the prediction curve for a given $x, x_{0}$ is the peak position in the $x$-axis (precipitation), and $b$ is the peak width. The concordance correlation coefficient and adjusted coefficient of determination $\left(R_{\mathrm{adj}}^{2}\right)$ were used as measures of model appropriateness and goodness of fit (Madden et al. 2007).

Relationship between soybean SSR and yield. A scatter plot was prepared to represent the yield as a function of DSI. To determine a DSI and a yield threshold, linear model, monophasic, and biphasic sigmoidal models were fitted to the data. Corrected Akaike information criterion (AICc) and $R_{\text {adj }}^{2}$ were used to compare the models' performance. Based on the relative information lost (AICc) and the $R_{\mathrm{adj}}^{2}$, the following biphasic model (equation 2) was selected:

$$
y=\beta_{1}+\left(\beta_{2}-\beta_{1}\right)\left[\frac{f}{\left(1+10^{x-E F_{1}}\right)}+\frac{1-f}{\left(1+10^{x-E F_{2}}\right)}\right]
$$

Where $\beta_{1}$ is the lower asymptote, $\beta_{2}$ is the upper asymptote, $f$ is the fraction of data associated with $E F_{1}, E F_{1}$ is the first inflection point, and $E F_{2}$ is the second inflection point. The concordance correlation coefficient and coefficient of determination were used as measures of model appropriateness and goodness of fit (Madden et al. 2007). The $x$ value at the first inflection point $\left(E F_{1}\right)$ was considered to be a DSI threshold, and the $y$ value at the first inflection point was considered to be a yield threshold. Therefore, a DSI of 22 ( $x$ value at the $E F_{1}$ ) was considered to be the DSI threshold, and yield values $>3,353 \mathrm{~kg} / \mathrm{ha}$ ( $y$ value at the $E F_{1}$ ) and $<3,353 \mathrm{~kg} / \mathrm{ha}$ were considered to be a relative yield gain and a relative yield loss, respectively (Table 1). All DSI values were standardized by subtracting 22 from each DSI value; therefore, a negative value for DSI and a positive value for DSI indicate a data point below and above the disease severity threshold, respectively. Scatter plots representing the relationship between the relative yield (gain and loss) and the standardized DSI were prepared.

To assess the reliability of using a DSI value of 22 to predict yield loss, a contingency table was used. A DSI of 22 or less (DSI+) was considered to be a prediction of yield gain $(\mathrm{Y}+)$. A DSI greater than 22 (DSI-) was considered to be a prediction of yield loss (Y-). Therefore, there were four possible outcomes. First, if the DSI was 22 or less (DSI+) and there was a yield gain (Y+), this was termed a "true positive." Second, if the DSI was 22 or less (DSI+) and there was a yield loss (Y-), this was termed a "false positive." Third, if the DSI was greater than 22 (DSI-) and there was a yield loss (Y-), this was termed a "true negative." Fourth, if the DSI was greater than 22 (DSI-) and there was a yield gain (Y+), this was termed a "false negative." The proportion of true positives (DSI+ and Y+) was regarded as a measure of sensitivity, the proportion of true negatives (DSI- and Y-) was regarded as a measure of specificity, and the overall accuracy was calculated as the number of correct assessments ([DSI+ and $\mathrm{Y}+]$ and [DSI- and $\mathrm{Y}-]$ ) divided by the number of all assessments. The likelihood ratio of positive prediction (LR+) was estimated by $\mathrm{LR}+=$ sensitivity/ $(1-$ specificity $)$, and the likelihood ratio of negative prediction (LR-) was estimated by LR- $=(1-$ sensitivity $) /$ specificity (Carisse et al. 2015; Fall et al. 2015; Madden et al. 2007).

Influence of selected weather variables on SSR threshold. Binary recursive partitioning in $\mathrm{R}$ packages (tree and rpart) was used to build a classification tree for disease severity (Ripley 2016). This process successively split the data along coordinate axes of explanatory variables so that, at any node, the split that maximally distinguished the response variable in the left and right branches was selected. The selected weather variables (Tp.J, Tp.JS, PP.J, PP. JS, Max.Tp.J, and Min.Tp.J) were assessed in turn, and the variables explaining the greatest amount of deviance in the DSI were selected. The smallest permitted node was 6 , and the node was not partitioned if the within-node deviance was $\leq 0.01$ of the root node (Ripley 2016). The two selected weather variables explaining the greatest amount of deviance were used to plot the classification tree. To construct the partition tree plot, a DSI $>22$ (as described above) was considered to be a high disease level, and a DSI of $\leq 22$ was considered to be a low disease level. Thus, the partition tree plot is a representation of SSR severity against the two selected weather variables explaining the greatest amount of deviance in the DSI (Ripley 2016).

The relationship between the disease severity level (high or low) and the selected weather variables was modeled with logistic regression (full model). Backward stepwise selection was used to select the significant regressor variables to include in the full model (McCullagh and Nelder 1989). The relationship between the disease severity level (high or low) and the two selected weather variables explaining the greatest amount of deviance based on the classification tree was modeled with logistic regression (proposed model). Models were developed using the generalized linear model (glm) function in the nlme package (version 3.1-124) with the binomial distribution. The disease severity level was considered a binary variable: 1 for high and 0 for low. The two models were compared in terms of the ratio (proposed model/full model) of their observed likelihood by using the log-likelihood ratio test (Madden et al. 2007). The log-likelihood of the ratio follows a $\chi^{2}$ distribution, with degrees of freedom equal to the difference in the number of parameters between the full model and the reduced model. The sample autocorrelation function was used to test autocorrelation in the residuals of two models (reduced and full model). The loglikelihood ratio statistic was then compared with a $\chi^{2}$ distribution. Also, the Akaike information criterion (AIC) and Bayesian information criterion (BIC) were used to compare the models. Because the $P$ value of the log-likelihood ratio statistic test was not significant (0.209) and because the reduced model had the lowest values for AIC and BIC, the reduced logistic regression model [logit(reduced model)] was chosen as a predictor. The estimated probability $(\hat{p})$ of having high disease severity for a given value of the two selected weather variables explaining the greatest amount of deviance was calculated as follows (Madden et al. 2007):

$$
\hat{p}=\frac{\exp ^{\text {logit }(\text { reduced model })}}{1+\exp ^{\text {logit }(\text { reduced model })}}
$$

A graphic representing the probability of having high disease severity for given values of the two selected weather variables was generated in the ranges in which data had been observed, in order to avoid any inappropriate extrapolation.

TABLE 1. Estimated parameters for the three-parameter lognormal equation describing the relationship between the Sclerotinia stem rot disease severity index (DSI) and the precipitation in July

\begin{tabular}{lrrr}
\hline Parameter $^{\mathrm{a}}$ & Estimate & Standard error & $P$ value $^{\mathrm{b}}$ \\
\hline$a$ & $5,023.380$ & 143.920 & $<0.0001$ \\
$b$ & 0.062 & 0.003 & $<0.0001$ \\
$x_{0}$ & 107.678 & 0.221 & $<0.0001$ \\
\hline
\end{tabular}

a Parameters: $a$ sets the amplitude of the prediction curve for a given amount of precipitation, $b$ is the peak width, and $x_{0}$ is the peak position in the $x$-axis (precipitation). The $x_{0}$ is an estimate of the amount of precipitation at the peak position (highest DSI).

b Significance code: $P<0.05$ 


\section{RESULTS}

Yield performance of maturity groups and varieties under SSR disease pressure. The maximum and minimum DSI by maturity group were 58.66 (maturity group 2.2) and 0 (maturity groups $1.4,1.5$, and 1.6 ), respectively. The DSI average by maturity group ranged between 5.84 (maturity group 1.4) and 17.27 (maturity group 2.8). The maximum and minimum yields were $5,084.06 \mathrm{~kg} / \mathrm{ha}$ (maturity group 2.9) and 2,192.33 kg/ha (maturity group 2.5), respectively. The yield average ranged between $3,278.36 \mathrm{~kg} / \mathrm{ha}$ (maturity group 2.6) and 3,671.21 kg/ha (maturity group 1.4). There was no significant difference between maturity groups across years in terms of yield $(P=0.618)$ and DSI $(P=0.671)$. However, the yields were $>3,100 \mathrm{~kg} / \mathrm{h}$ a for all years for maturity groups 1.4 and 3.1 , while DSI ranged between 0 and 40.48 for maturity group 1.4 and from 4.73 to 18.30 for maturity group 3.1. (Supplementary Fig. S1). The average yields for maturity groups 1.4 and 3.1 were $3,606.72 \mathrm{~kg} / \mathrm{ha}$ (53.74 bushels/acre [bu/A]) and 3,516.64 kg/ha (52.39 bu/A), respectively. The yield for the variety Vinton 81 was significantly lower in comparison with the other varieties $(P=0.002)$, with an average yield of $2,313.57 \mathrm{~kg} / \mathrm{ha}(34.50 \mathrm{bu} / \mathrm{A})$ and an average of DSI of 14.6. However, the mean yields among the other varieties were not significantly different $(P=0.853)$.
Relationship between SSR severity and selected weather variables. The correlations between the DSI and the weather variables (Tp.J, Tp.JS, Max.Tp.J, Min.Tp.J, PP.J, and PP.JS) were significant (Fig. 1). The correlation between the DSI and precipitation was positive (Fig. 1), whereas the correlation between the DSI and air temperature was negative (Fig. 1). The Tp.J was the weather variable with the highest correlation with the DSI ( $r=$ $-0.56, P<0.001)$. The PP.J was significantly correlated with DSI $(r=0.15, P<0.001)$. Also, the relationship between the DSI and the PP.J was described by a four-parameter lognormal function $\left(R_{\mathrm{adj}}^{2}=\right.$ 0.77 , concordance correlation coefficient $=0.63)($ Fig. 2$)$. The $x_{0}$ in the lognormal equation, which is an estimate of the amount of precipitation at the peak position (highest DSI), was $108 \mathrm{~mm}$ (Table 1).

Relationship between SSR and yield. There was a significant negative correlation between the DSI and the yield $(r=-0.61$, $P<0.001$ ) (Fig. 1). Monophasic, biphasic sigmoidal, and linear model all significantly $(P<0.000)$ described the relationship between the DSI and the yield. The AICc for the linear, monophasic, and biphasic models were $10045.89,10171.61$, and 10015.57, respectively. The $R_{\text {adj }}^{2}$ for the linear, monophasic, and biphasic models were 0.36 , 0.32 , and 0.26 , respectively. There was a sigmoidal relationship between the yield and the DSI. For all 11 years, the yield decreased as

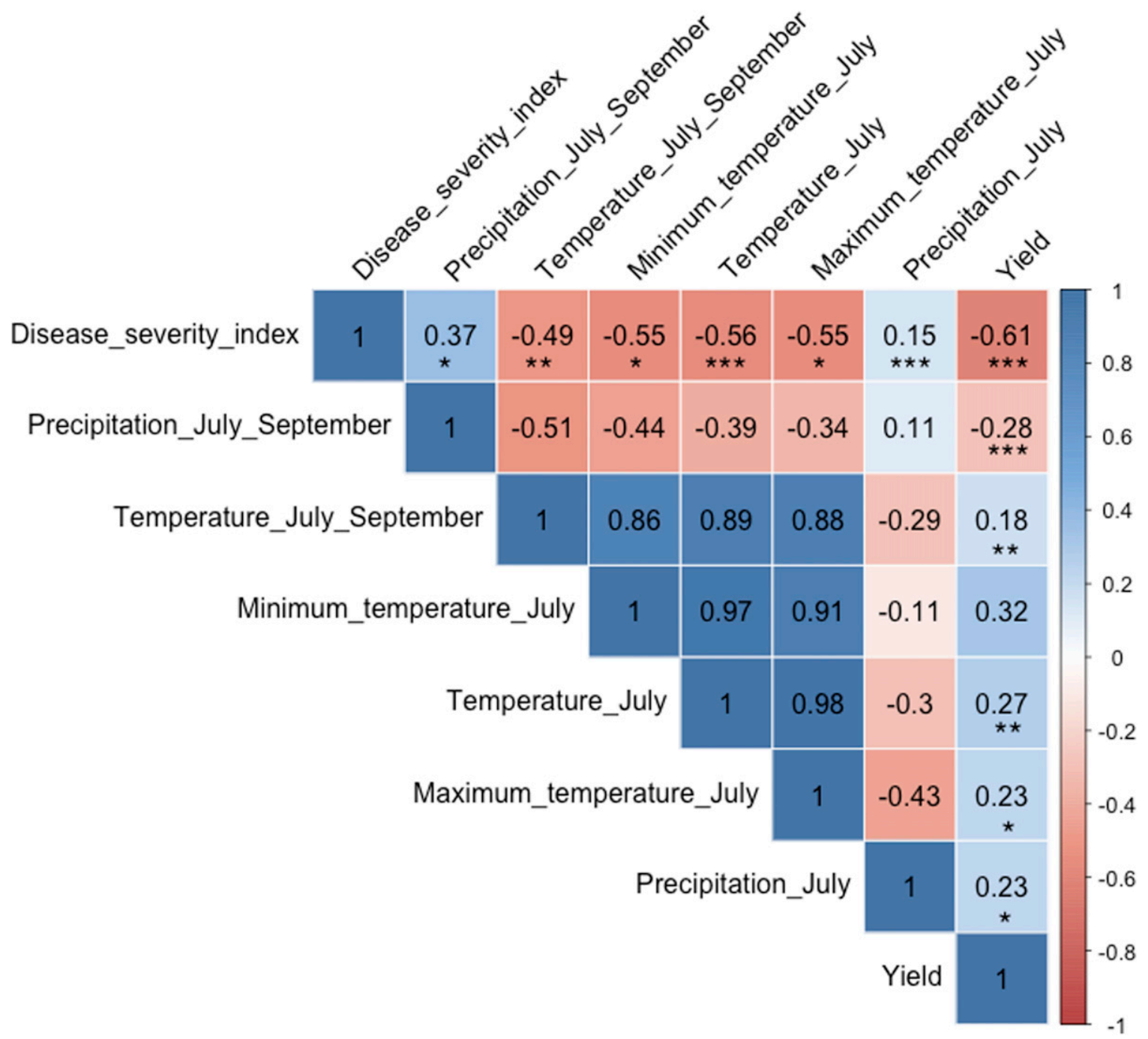

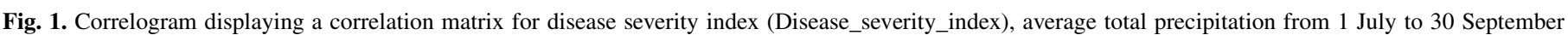

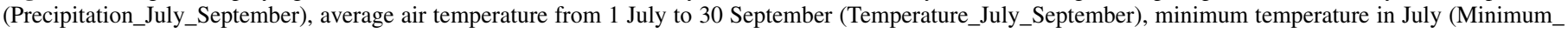

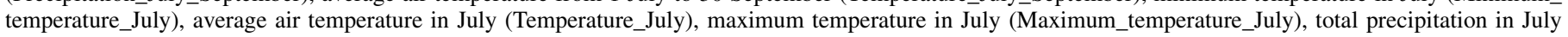

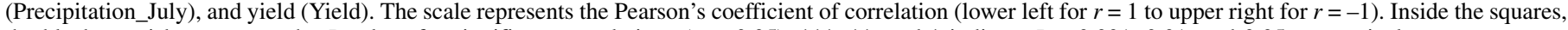
the black asterisks represent the $P$ values for significant correlations $(\alpha=0.05)$ : ***, $* *$, and $*$ indicate $P<0.001,0.01$, and 0.05 , respectively. 
the DSI increased (Fig. 3). The first inflection point was at a DSI of 22 and, when the DSI increased from 22.0 to 24.2 (10\% increase), the yield decreased from $3,308.14$ to $2,951.29 \mathrm{~kg} / \mathrm{ha}$ ( $11 \%$ decrease) (Table 2; equation 2). The second inflection point was at a DSI of 57 and, when the DSI increased from 57 to 62.7 (10\% increase), the yield decreased from $2,723.19$ to $2,289.35 \mathrm{~kg} / \mathrm{ha}$ ( $16 \%$ decrease) (Table 2; equation 2). When the DSI was $<22$, the yield was $\geq 3,353 \mathrm{~kg} / \mathrm{ha}$ and, when the DSI was $>22$, the yield was $<3,353 \mathrm{~kg} / \mathrm{ha}$ (Fig. 4 ). The overall accuracy (correct assessment) of using a DSI of 22 as an SSR threshold for relative yield loss $(<3,353 \mathrm{~kg} / \mathrm{ha}$ ) and gain ( $\geq 3,353 \mathrm{~kg} / \mathrm{ha}$ ) was 0.72 . Using this DSI threshold led to $95 \%$ (sensitivity) of yield gain events being correctly predicted (Fig. 4; Table 3 ). The positive and negative likelihood ratios of using this DSI threshold for yield prediction were 2.7 and 0.12 , respectively (Table 3 ).

Influence of selected weather variables on SSR threshold. The Tp.J and PP.J were associated with the disease severity level (Table 4; Supplementary Figure S2). The Tp.J and PP.J were used in the reduced logistic regression model and were statistically significant (Table 5). When the Tp.J was $>19.5^{\circ} \mathrm{C}$, the disease severity was low in $98 \%$ of the cases $(n=459)$ (Table 4$)$. The probability of having high disease severity decreased when the Tp.J was $>19.5^{\circ} \mathrm{C}$ (Fig. 5). Once the Tp.J was $\leq 19.5^{\circ} \mathrm{C}$ and the PP.J was $\leq 108.5 \mathrm{~mm}$ (but $>20 \mathrm{~mm}$ ), the disease severity was high in $92 \%$ of the cases $(n=164)$ (Table 4$)$. However, a Tp.J of $\leq 19.5^{\circ} \mathrm{C}$ and a PP.J $>108.5 \mathrm{~mm}$ led to low disease severity in $96 \%$ of the cases $(n=$ 152) (Table 4). Regardless of the precipitation in July, the disease severity was low when the Tp.J was $>21^{\circ} \mathrm{C}$, with low probability of having high disease severity (Fig. 5).

\section{DISCUSSION}

A large amount of scientific literature has shown the descriptive and predictive role of epidemiology, which has served to identify and quantify factors that cause spatial and temporal increases in disease intensity. Therefore, epidemiology has played a major role in the adoption of sustainable agriculture practices by exploring links between plant disease epidemiology and management systems. Since the early work of J. E. Van der Plank (1963), which popularized the concept of modeling epidemics in time and led to the publication of major plant epidemiology books (Campbell and Madden 1990; Madden and Hughes 2002; Madden et al. 2007), the number of publications on the quantification of plant disease has grown considerably over the last two decades (Forbes et al. 2009). These books propose a number of statistical and epidemiological approaches that have been used to answer questions about epidemiology and define strategies for managing important pathogens and

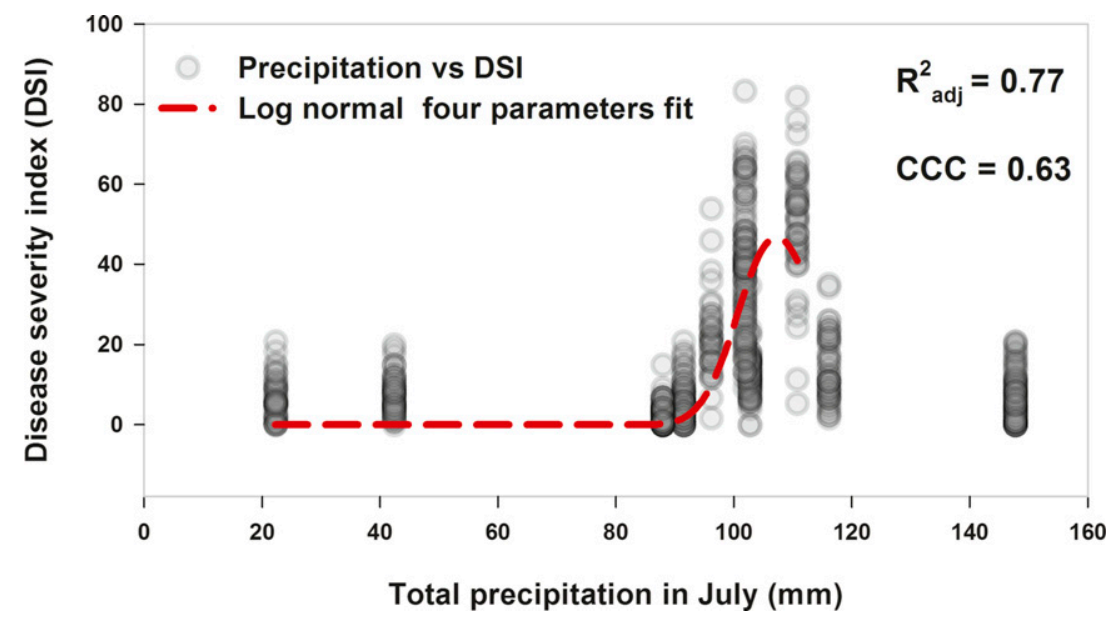

Fig. 2. Relationship between the disease severity index (DSI) and the total precipitation in July (in millimeters), produced with 11 years of Sclerotinia stem rot observation data. The concordance correlation coefficient (CCC) and adjusted coefficient of determination $\left(R_{\mathrm{adj}}^{2}\right)$ were used as measures of model appropriateness and goodness of fit.

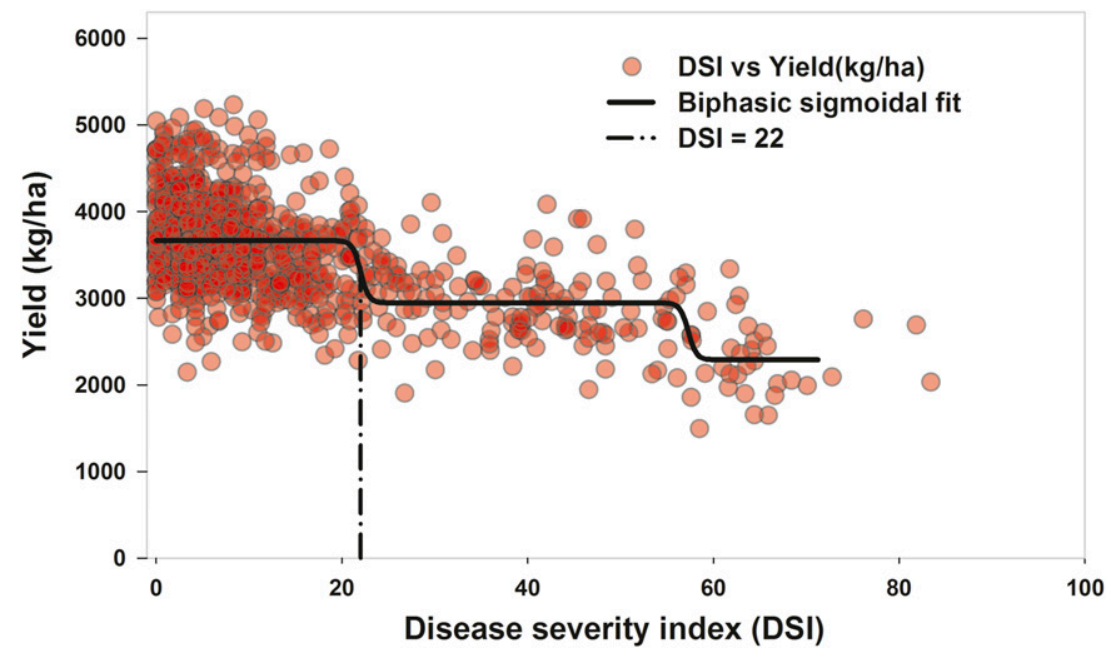

Fig. 3. Relationship between the yield and the disease severity index (DSI) for all 11 years of Sclerotinia stem rot observation data. Each data point represents the average yield and disease pressure values for individual varieties and years. The $x$ value of the first inflection point $\left(E F_{1}\right)$ is DSI $=22$, and the $y$ value of $E F_{1}$ is yield $=3,353 \mathrm{~kg} / \mathrm{ha}$. 
diseases in many pathosystems. For example, De Wolf et al. (2003) used nonparametric correlation and stepwise logistic regression analysis to develop a risk assessment model for wheat Fusarium head blight epidemics, with a sensitivity of $100 \%$ and a specificity

TABLE 2. Estimated parameters for the biphasic sigmoidal equation describing the relationship between yield and the disease severity index

\begin{tabular}{lrcc}
\hline Parameter $^{\mathrm{a}}$ & Estimate & Standard error & $P$ value $^{\mathrm{b}}$ \\
\hline$\beta_{1}$ & $2,289.350$ & 97.509 & $<0.0001$ \\
$\beta_{2}$ & $3,664.606$ & 21.408 & $<0.0001$ \\
$f$ & 0.522 & 0.050 & $<0.0001$ \\
$E F_{1}$ & 22.006 & 0.378 & $<0.0001$ \\
$E F_{2}$ & 57.288 & 0.644 & $<0.0001$ \\
\hline
\end{tabular}

a Parameters: $\beta_{1}$ is the lower asymptote, $\beta_{2}$ is the upper asymptote, $f$ is the fraction of data associated with $E F_{1}$ (the first inflection point), and $E F_{2}$ is the second inflection point.

b Significance code: $P<0.05$ of $85 \%$ (Giroux et al. 2016). Avelino et al. (2006) used epidemiological knowledge to provide an understanding of how intensifying Coffea arabica cultivation increases the risk of a serious coffee rust epidemic. For soybean management, epidemiological studies by Mila et al. $(2003,2004)$ helped to identify important weather variables that drive SSR prevalence in the U.S. Midwest. Our article has presented an epidemiological case study that shows how epidemiological knowledge can help to define plant disease management strategies and bridge the gap between theory and practice. The epidemiological approach was used to examine historical disease data and metadata to advance our understanding of SSR development and improve SSR management systems. Within the last two decades, S. sclerotiorum has become a significant threat to soybean production, especially in the upper Midwest of the United States. To develop a complete and effective disease management program, it is crucial to improve our understanding of the actual risk of disease development (Mahaffee
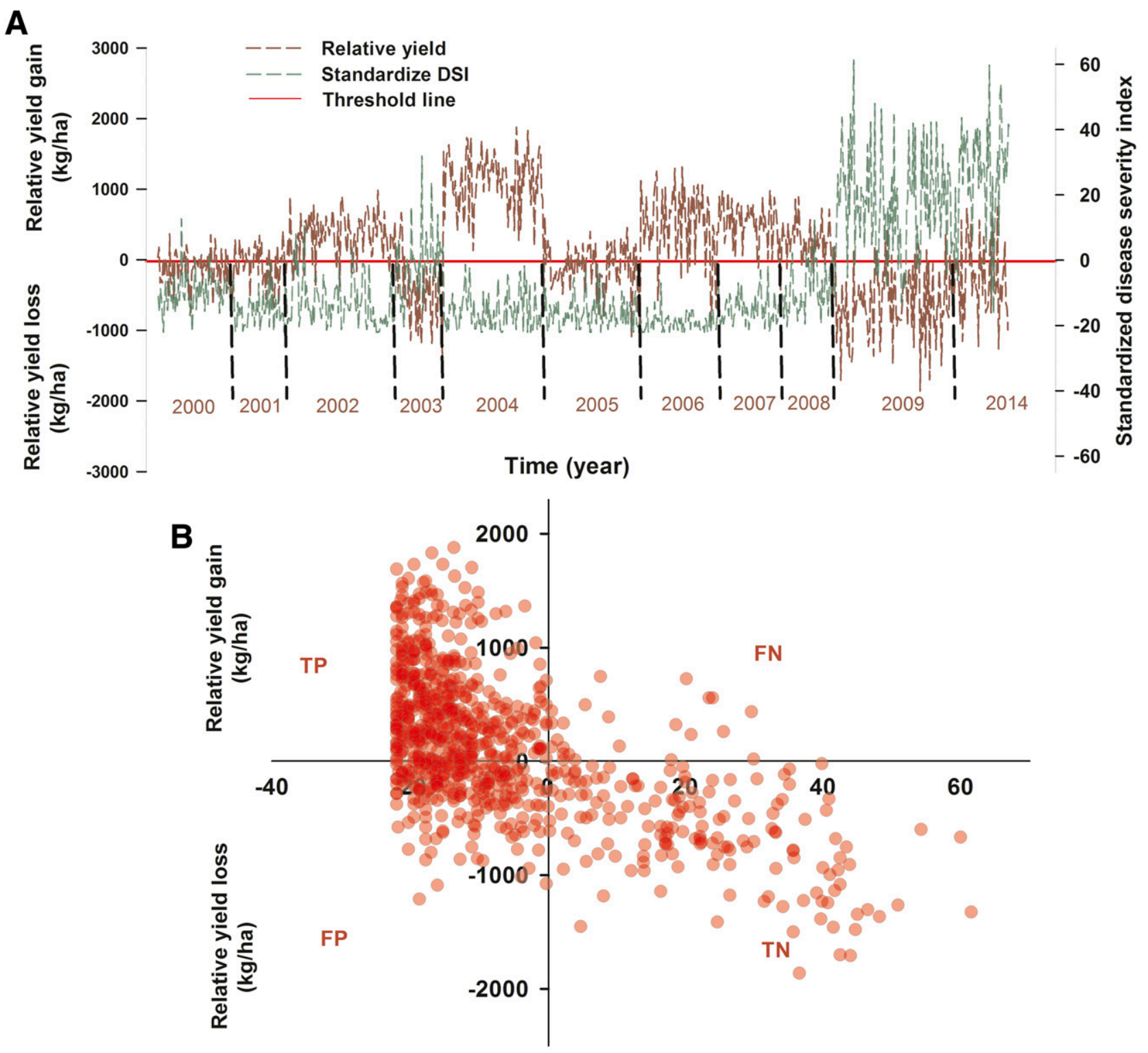

Standardized disease severity index

Fig. 4. Relative yield (loss/gain) $\mathbf{A}$, as a function of time and $\mathbf{B}$, of standardized disease severity index (DSI). The threshold line (horizontal 0 line) represents a yield of $3,353 \mathrm{~kg} / \mathrm{ha}$ and a DSI of 22 . Yield values $>3,353 \mathrm{~kg} / \mathrm{ha}$ were considered a relative gain and yield values $<3,353 \mathrm{~kg} / \mathrm{ha}$ were considered a relative loss. To build these graphics, all DSI values were standardized by subtracting 22 (which is the DSI threshold at which significant yield loss is detected) from each DSI value. $\mathrm{TP}=$ true positive, $\mathrm{TN}=$ true negative, $\mathrm{FP}=$ false positive, and $\mathrm{FN}=$ false negative . 
and Stoll 2016). This process includes identifying environmental predictors of epidemics and yield loss.

To determine a pooled data set in order to identify environmental predictors of epidemics, yield performance of maturity groups and varieties under SSR pressure was analyzed. The maturity group performance analysis showed no significant difference between maturity groups in terms of the yield and DSI. However, regardless of disease pressure, the early-maturity group 1.4 and late-maturity group 3.1 consistently yielded $>3,100 \mathrm{~kg} / \mathrm{ha}$ (46.2 bu/A), which is more than the annual soybean yield average for the United States from 1960 to 2014 and for Michigan from 2006 to 2014 (3,039.7 kg/ha or $45.2 \mathrm{bu} / \mathrm{A})$ (Irwin and Good 2014). Differences in the flowering period between maturity groups may partially explain the performance of maturity groups 1.4 and 3.1. Field observations suggest that an early-maturity group can avoid SSR by completing flowering before the period that is critical for SSR development. A comparison of mean yields among varieties indicated that the yield of Vinton 81 was significantly lower in comparison with other varieties. This result is supported by the findings of Delate et al. (2003) that Vinton 81 produced low yields. However, Arahana et al. (2001) suggested that Vinton 81 was less susceptible to SSR. Therefore, it is important to know how SSR severity will impact soybean yield.

SSR severity in soybean was negatively correlated with yield, which decreased as disease severity increased. The relationship between these two variables (DSI and yield) was described by a biphasic sigmoidal model. Therefore, for a $10 \%$ increment in the DSI of SSR, the yield was reduced by $11 \%$ (decreased from
$3,308.14$ to $2,951.29 \mathrm{~kg} / \mathrm{ha}$ ). These findings can be compared with previous studies, some recent, that suggested a yield reduction of 133 to $333 \mathrm{~kg} / \mathrm{ha}$ for every $10 \%$ increment in SSR incidence (Danielson et al. 2004; Hoffman et al. 1998; Lehner et al. 2016; Yang et al. 1999). Results reported in studies conducted in the U.S. Midwest and in Brazil claimed a relative yield loss that varied from 4.5 to $8.4 \%$ for every $10 \%$ increase in SSR incidence (Chun et al. 1987; Hoffman et al. 1998; Lehner et al. 2016; Yang et al. 1999). However, instead of using incidence, DSI was used in the present study, which encompasses the cumulative effect of epidemic progression in infected plants (Savary et al. 2006). Consequently, the relative yield loss that results from a $10 \%$ unitary increase in SSR incidence is lower than the yield loss associated with the same unitary increase in the SSR severity index. Analysis of the relationship between the SSR severity index and yield suggested that a DSI of 22 seems to be a threshold for relative yield loss $(<3,353 \mathrm{~kg} / \mathrm{ha})$ and gain $(\geq 3,353 \mathrm{~kg} / \mathrm{ha})$. Throughout the 11 years of this study, almost every time that the DSI was above the threshold (DSI of 22), a relative yield loss was observed ( $<3,353 \mathrm{~kg} / \mathrm{ha})$. The overall accuracy of using a DSI of 22 as a threshold for relative yield loss was 0.72 , and using this DSI threshold led to $95 \%$ of yield gain events being correctly predicted. This is the first time that an SSR severity index threshold has been proposed for soybean yield loss. This threshold defines the limit between a high disease severity level (DSI > 22) and a low disease severity level (DSI $\leq 22)$ and, hence, the threshold is probably a reflection of the severity rating scale ( 0 to 3$)$. Indeed, the rating scale takes soybean plant architecture into account and, thus, low DSI numbers reflect the

TABLE 3. Assessment of the reliability of using a disease severity index (DSI) greater than 22 as an indicator of yield loss due to Sclerotinia stem rot in soybean

\begin{tabular}{|c|c|c|c|c|c|c|c|c|}
\hline \multirow[b]{2}{*}{ DSI } & \multicolumn{3}{|c|}{ Yield $(\mathrm{kg} / \mathrm{ha})^{\mathrm{a}}$} & \multirow[b]{2}{*}{ Overall accuracy ${ }^{\mathrm{b}}$} & \multirow[b]{2}{*}{ Sensitivity ${ }^{\mathrm{b}}$} & \multirow[b]{2}{*}{ Specificity $^{\mathrm{b}}$} & \multirow[b]{2}{*}{$\mathrm{LR}+^{\mathrm{c}}$} & \multirow[b]{2}{*}{ LR-c } \\
\hline & $\mathrm{Y}+$ & $\mathrm{Y}-$ & Total & & & & & \\
\hline DSI+ & 426 & 23 & 449 & $\ldots$ & $\ldots$ & $\ldots$ & $\ldots$ & $\ldots$ \\
\hline DSI- & 200 & 156 & 356 & . & . & $\ldots$ & . & $\ldots$ \\
\hline
\end{tabular}

a DSI $\leq 22$ (DSI+) was considered to be a prediction of yield $>3,353 \mathrm{~kg} / \mathrm{ha}(50 \mathrm{bu} / \mathrm{A})(\mathrm{Y}+)$ and DSI $>22$ (DSI-) was considered to be a prediction of yield $<3,353$ $\mathrm{kg} / \mathrm{ha}(50 \mathrm{bu} / \mathrm{A})(\mathrm{Y}-)$.

b The proportion of true positives (DSI+ and $\mathrm{Y}+$ ) was regarded as a measure of sensitivity, the proportion of true negatives (DSI- and Y-) was regarded as a measure of specificity, and the overall accuracy was calculated as the number of correct assessments ([DSI+ and Y+] and [DSI- and Y-]) divided by the number of all assessments.

${ }^{c}$ LR+ and LR- are the positive likelihood ratio and negative likelihood ratio, respectively; LR $+=$ sensitivity/( $1-$ specificity $)$ and LR- $=(1-$ sensitivity $) /$ specificity.

TABLE 4. Occurrence of high-disease-level events and low-disease-level events against average air temperature in July (Tp.J) and precipitation in July (PP.J) ${ }^{\mathrm{a}}$

\begin{tabular}{lccc}
\hline & \multicolumn{2}{c}{ Temperature and precipitation thresholds ${ }^{\mathrm{b}}$} \\
\cline { 2 - 4 } Disease level & $\mathrm{Tp.J}<19.5^{\circ} \mathrm{C}$ and $20 \mathrm{~mm}>$ PP.J $<108 \mathrm{~mm}$ & $\mathrm{Tp} . \mathrm{J}<19.5^{\circ} \mathrm{C}$ and PP.J $>108 \mathrm{~mm}$ & \multicolumn{1}{c}{ Tp.J $>19.5^{\circ} \mathrm{C}$ and PP.J $>20 \mathrm{~mm}$} \\
\hline High disease $(n)$ & 15 & 152 & 9 \\
Low disease $(n)$ & 15459 \\
\hline a Data from 11 years of Sclerotinia stem rot observations were pooled. A disease severity index (DSI) $>22$ defines a high-disease-level event as one that results in \\
significant yield loss. Therefore, a DSI $>22$ was considered high and a DSI $<22$ was considered low. The total number of cases was $n=805$. To define thresholds, \\
a partition tree plot was used to represent DSI level against the two selected weather variables (Tp.J and PP.J) explaining the greatest amount of deviance in the \\
DSI (Ripley 2016).
\end{tabular}

TABLE 5. Variables selected by logistic regression analysis of the disease severity level and weather variables

\begin{tabular}{lcccc}
\hline Variables $^{\mathrm{a}}$ & Estimate & $\mathrm{SE}^{\mathrm{b}}$ & $P$ value & \multicolumn{1}{c}{ Reduced model $^{\mathrm{d}}$} \\
\hline Intercept & 197.33 & 2.502 & $<0.0001$ & \\
Tp.J & -9.77 & 1.24 & $<0.0001$ & $\frac{p}{1-p}=197.33-9.77 * T p . J-176 * P P . J+0.09 * T p . J * P P . J$ \\
PP.J & -1.76 & 0.24 & $<0.0001$ & \\
Tp.J.PP.J & 0.09 & 0.01 & $<0.0001$ & \\
\hline
\end{tabular}

${ }^{a} \mathrm{Tp} . J$ is the average temperature in July, PP.J is the total precipitation in July, and Tp.J:PP.J is the interaction between TP.J and PP.J.

b Standard error.

c Significance code: $P<0.05$.

d Symbol $p$ is the probability of having a disease severity index $>22$. 
infection of mainly lateral branches, which will have less impact on yield. Therefore, to make this threshold useful and reliable for SSR management strategies, it is imperative to understand how environmental variables influence the SSR severity index level.

Under the weather conditions in Sanilac County, MI, PP.J and Tp.J were significantly correlated with DSI, and Tp.J was the weather variable with the highest correlation with DSI $(r=-0.56)$. Similar observations made in different pathosystems and locations indicate that the amount of precipitation around the flowering period (July in Sanilac County, MI) has a significant effect on disease occurrence (Haas and Bolwyn 1972; Mila et al. 2003; Moore 1955; Twengström et al. 1998). In addition, Mila et al. (2001) demonstrated that the absolute value of the average air temperature parameter was significantly higher than the value of the July precipitation parameter. However, Workneh and Yang (2000) reported that July precipitation was not a limiting factor for SSR development in the north-central region of the United States. A four-parameter lognormal was found to describe the relationship between the DSI and the PP.J. The DSI increased as the PP.J increased; however, when the PP.J was $>108 \mathrm{~mm}$, the DSI decreased. Indeed, depending on soil type and topography, heavy rainfall $(>100 \mathrm{~mm})$ can waterlog fields and, consequently, result in $100 \%$ mortality of S. sclerotiorum sclerotia within 16 to 31 days (Hooker 1981; Saharan and Mehta 2008). In summary, all studies pointed to average air temperature as the weather variable that plays a major role in SSR development but, in addition, our data suggest a significant and high correlation between the minimum and maximum temperatures in July and SSR. However, for management purposes, it is more relevant to have a quantitative description of how these weather variables drive the SSR severity index level.

Instead of using SSR incidence (Mila et al. 2003, 2004), SSR severity was used as a response variable to build a logistic prediction model. The recursive partitioning results suggest that the Tp.J and PP.J were the most significant variables associated with the disease severity level. In $98 \%$ of the cases, a Tp.J $>19.5^{\circ} \mathrm{C}$ was associated with low disease severity, and the probability of having high disease severity decreased as the Tp.J decreased. Also, a high SSR severity level was observed with a low Tp.J $\left(\leq 19.5^{\circ} \mathrm{C}\right)$ and a moderate PP.J $(20 \mathrm{~mm}<$ PP.J $\leq 108.5 \mathrm{~mm})$, whereas low SSR severity was observed with a high Tp.J $\left(>21^{\circ} \mathrm{C}\right)$ regardless of the total amount of precipitation. In summary, Tp.J and PP.J significantly affected the strength and magnitude of SSR severity and the subsequent yield loss. These results corroborate previous findings (Mila et al. 2001,
2003, 2004), and the environmental predictors of SSR epidemics and yield losses were quantitatively identified and defined.

To our knowledge, this is the first study to describe quantitatively how Tp.J and PP.J can influence SSR severity and yield loss under field conditions. This study confirms the necessity of having different, site-specific approaches to predict SSR intensity at the field level, as suggested by Mila et al. (2004). The results of this study should be helpful for economic risk assessments associated with the development of SSR in soybean and, therefore, it is imperative to determine estimates of disease losses in order to develop any economic disease management program (Nutter and Guan 2001). Our results suggest a site-specific yield threshold (3,353 kg/ha) that is above what was found by Lehner et al. (2016) $(3,000 \mathrm{~kg} / \mathrm{ha})$ as an expected yield in the absence of SSR and that is also higher than the annual U.S. average soybean yield (3,039.7 kg/ha). Also, reliable estimates of abiotic and abiotic-induced crop losses will help to define priorities in order to optimize the returns on disease management (Nutter and Guan 2001). In this context, the results of this study lay the groundwork for the future use of a DSI threshold of 22 , a Tp.J of $19.5^{\circ} \mathrm{C}$, and the PP.J as risk indicators for SSR intensity. This threshold allows soybean stakeholders to assess the value of disease control and establish an SSR baseline (e.g., a DSI of 22) in order to achieve cost-effective protection of yield. In addition, these findings can help with building an infection model for SSR as a supplement to an apothecia prediction model for determining the optimal time to apply fungicide. Nevertheless, further research should be done to validate these risk indicators and assess how they can be integrated into a tactical SSR management strategy in soybean. In the context of current and future climate change worldwide, the results of this long-term study highlight the potential impact of specific weather events on SSR and improve our understanding of how weather variables may lead to SSR outbreaks in soybean. In most of the pathosystems involving S. sclerotiorum, epidemiological data have historically been generated by universities, research centers, and university extension services. Therefore, the epidemiological approaches presented in this study can be readily applied in each of these pathosystems to examine historical disease data and metadata in order to improve our understanding and management of disease caused by $S$. sclerotiorum. Analyses such as those used in this study are important for understanding the multiple factors that influence epidemics; however, such analyses are generally challenging because they incorporate data collected at different spatial and temporal scales and with different patterns of spatial and temporal correlation. In plant disease epidemiology, as in ecology more broadly,

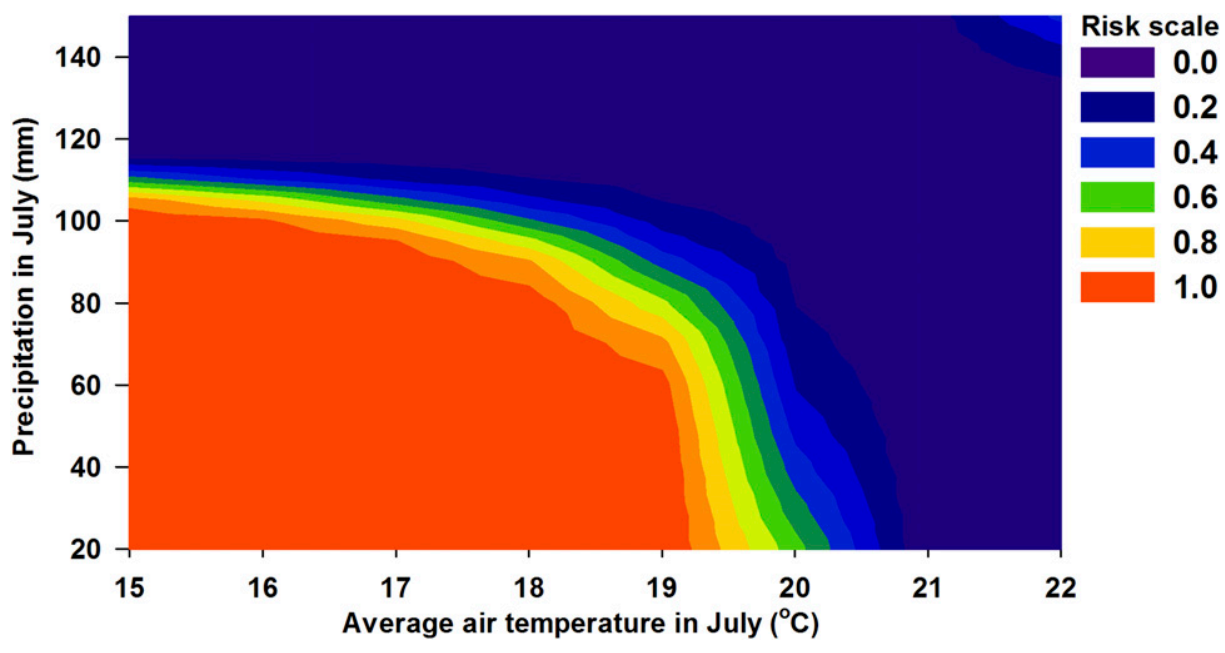

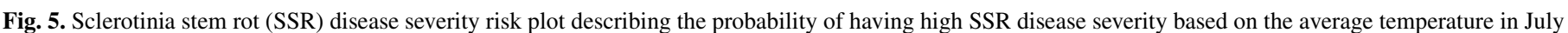

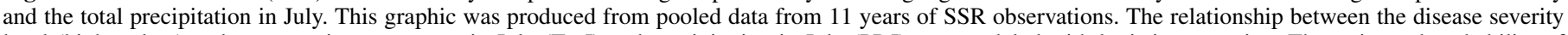

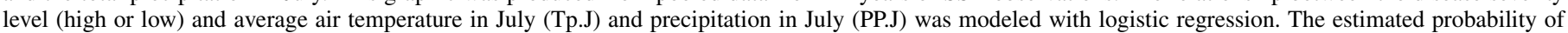

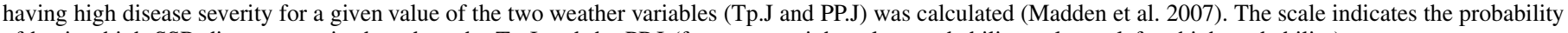
of having high SSR disease severity based on the Tp.J and the PP.J (from upper right $=$ low probability to lower left $=$ high probability). 
there are ongoing debates about appropriate methods for evaluating such data. Since the publication of Hurlbert (1984), several statistical methods have been proposed and debated (Hurlbert 2004; Oksanen $2001,2004)$ to overcome the issue of multiple observations with different patterns of spatiotemporal correlation (Bell 1999; Chaves 2010; Garrett et al. 2004; Olden et al. 2008; Roff and Roff 2003; Sullivan et al. 2006). Analyzing these types of data requires careful hypotheses definitions, scale of application, and, more importantly, being aware of the limits of statistical inferences.

\section{ACKNOWLEDGMENTS}

We thank O. Carisse of Agriculture and Agri-Food Canada for editing the manuscript and providing statistical advice, and J. J. Jacobs and A. M. Byrne for their support and advice.

\section{LITERATURE CITED}

Abawi, G. S., and Grogan, R. G. 1975. Source of primary inoculum and effects of temperature and moisture on infection of bean by Whetzelinia sclerotiorum. Phytopathology 65:300-309.

Adams, P. B., and Ayers, W. A. 1979. Ecology of Sclerotinia Species. Phytopathology 69:896-899.

Aldrich-Wolfe, L., Travers, S., and Nelson, B. D., Jr. 2015. Genetic variation of Sclerotinia sclerotiorum from multiple crops in the North Central United States. PLoS One 10:e0139188.

Arahana, V. S., Graef, G. L., Specht, J. E., Steadman, J. R., and Eskridge, K. M. 2001. Identification of QTLs for resistance to Sclerotinia sclerotiorum in soybean. Crop Sci. 41:180-188.

Avelino, J., Zelaya, H., Merlo, A., Pineda, A., Ordonez, M., and Savary, S. 2006. The intensity of a coffee rust epidemic is dependent on production situations. Ecol. Modell. 197:431-447.

Bell, J. F. 1999. Tree-based methods. Pages 89-105 in: Machine Learning Methods for Ecological Applications. A. H. Fielding, ed. Springer, Kluwer, Dordrecht, The Netherlands.

Boland, G. J., and Hall, R. 1988. Relationships between the spatial pattern and number of apothecia of Sclerotinia sclerotiorum and stem rot of soybean. Plant Pathol. 37:329-336.

Bolton, M. D., Thomma, B. P. H. J., and Nelson, B. D. 2006. Sclerotinia sclerotiorum (Lib.) de Bary: Biology and molecular traits of a cosmopolitan pathogen. Mol. Plant Pathol. 7:1-16.

Calvin, H., Newton, C., and Sequeira, L. 1972. The Plant Disease Reporter / Issued by the Plant Disease Survey. Bureau of Plant Industry, United States Department of Agriculture, Washington, DC.

Campbell, C. L., and Madden, L. V. 1990. Introduction to Plant Disease Epidemiology. Wiley-Interscience, New York.

Carisse, O., Caffi, T., and Rossi, V. 2015. How to develop and validate plant disease forecasting systems. Pages 239-248 in: Exercises in Plant Disease Epidemiology, 2nd ed. K. L. Stevenson and M. J. Jeger, eds. American Phytopathological Society Press, St. Paul, MN.

Chaves, L. F. 2010. An entomologist guide to demystify pseudoreplication: Data analysis of field studies with design constraints. J. Med. Entomol. 47:291-298.

Chun, D., Kao, L. B., Lockwood, J. L., and Isleib, T. G. 1987. Laboratory and field assessment of resistance in soybean to stem rot caused by Sclerotinia sclerotiorum. Plant Dis. 71:811-815.

Clarkson, J. P., Fawcett, L., Anthony, S. G., and Young, C. 2014. A model for Sclerotinia sclerotiorum infection and disease development in lettuce, based on the effects of temperature, relative humidity and ascospore density. PLoS One 9:e94049.

Danielson, G. A., Nelson, B. D., and Helms, T. C. 2004. Effect of Sclerotinia stem rot on yield of soybean inoculated at different growth stages. Plant Dis. 88:297-300.

de Bary, A. 1886. Ueber einige Sclerotinien und Sclerotienkrankheiten. Bot. Z. 44:374-474

de Bary, A. 1887. Comparative Morphology and Biology of the Fungi, Mycetozoa and Bacteria. Clarendon Press, Oxford.

De Wolf, E. D., Madden, L. V., and Lipps, P. E. 2003. Risk assessment models for wheat Fusarium head blight epidemics based on within-season weather data. Phytopathology 93:428-435.

Delate, K., Burcham, B., and Friedrich, H. 2003. Evaluation of soybean varieties for certified organic production-Neely-Kinyon Trial, 2002. Report ISRF02-12. Armstrong Research and Demonstration Farm, Iowa State University, Ames.

Fall, M. L., Van der Heyden, H., Beaulieu, C., and Carisse, O. 2015. Bremia lactucae infection efficiency in lettuce is modulated by temperature and leaf wetness duration under Quebec field conditions. Plant Dis. 99:1010-1019.
Fernando, W. G. D., Nakkeeran, S., and Zhang, Y. 2004. Ecofriendly methods in combating Sclerotinia sclerotiorum (Lib.) de Bary. Recent Res. Dev. Environ. Biol. 1:329-347.

Forbes, G. A., Mizubuti, E. S. G., and Shtienberg, D. 2009. Plant disease epidemiology and disease management - Has science had an impact on practice? Pages 351-368 in: Integrated Pest Management: InnovationDevelopment Process, Vol. 1. R. Peshin and A. K. Dhawan, eds. Springer, Dordrecht, The Netherlands.

Garg, H., Li, H., Sivasithamparam, K., Kuo, J., and Barbetti, M. J. 2010. The infection processes of Sclerotinia sclerotiorum in cotyledon tissue of a resistant and a susceptible genotype of Brassica napus. Ann. Bot. 106: 897-908.

Garrett, K. A., Madden, L. V., Hughes, G., and Pfender, W. F. 2004. New applications of statistical tools in plant pathology. Phytopathology 94: 999-1003.

Giroux, M.-E., Bourgeois, G., Dion, Y., Rioux, S., Pageau, D., Zoghlami, S., Parent, C., Vachon, E., and Vanasse, A. 2016. Evaluation of forecasting models for Fusarium head blight of wheat under growing conditions of Quebec, Canada. Plant Dis. 100:1192-1201.

Grau, C. R., Radker, V. L., and Gillespie, F. L. 1982. Resistance of soybean cultivars to Sclerotinia sclerotiorum. Plant Dis. 66:506-508.

Haas, J. H., and Bolwyn, B. 1972. Ecology and epidemiology of Sclerotinia wilt of white beans in Ontario. Can. J. Plant Sci. 52:525-533.

Hartill, W. F. T. 1980. Aerobiology of Sclerotinia sclerotiorum and Botrytis cinerea spores in New Zealand tobacco crops. N. Z. J. Agric. Res. 23: 259-262.

Hartman, G. L., Rupe, J. C., Sikora, E. J., Domier, L. L., Davis, J. A., and Steffey, K. L., eds. 2015. Compendium of Soybean Diseases and Pests, 5th ed. American Phytopathological Society Press, St. Paul, MN.

Hoffman, D. D., Hartman, G. L., Mueller, D. S., Leitz, R. A., Nickell, C. D., and Pedersen, W. L. 1998. Yield and seed quality of soybean cultivars infected with Sclerotinia sclerotiorum. Plant Dis. 82:826-829.

Hooker, W. J. ed. 1981. Compendium of Potato Diseases. American Phytopathological Society, St. Paul, MN.

Hurlbert, S. H. 1984. Pseudoreplication and the design of ecological field experiments. Ecol. Monogr. 54:187-211.

Hurlbert, S. H. H. 2004. On misinterpretations of pseudoreplication and related matters: A reply to Oksanen. Oikos 104:591-597.

Irwin, S., and Good, D. 2014. The 2014 U.S. average soybean yield: Headed for a new record? Farmdoc Daily 4:137. http://farmdocdaily.illinois.edu/ pdf/fdd230714.pdf

Jones, D. 1976. Infection of plant tissue by Sclerotinia sclerotiorum: A scanning electron microscope study. Micron 7:275-279.

Koenning, S. R., and Wrather, J. A. 2010. Suppression of soybean yield potential in the continental United States by plant diseases from 2006 to 2009. Online publication. Plant Health Prog. doi.org/10.1094/PHP-20101122-01-RS

Lehner, M. S., Pethybridge, S. J., Meyer, M. C., and Del Ponte, E. M. 2016. Meta-analytic modeling of the incidence-yield and incidence-sclerotial production relationships in soybean white mold epidemics. Plant Pathol. 66: 460-468.

Logan, M. 2010. Biostatistical Design and Analysis Using R: A Practical Guide. Wiley-Blackwell, Chichester, UK.

Lumsden, R. D., and Wergin, W. P. 1980. Scanning-electron microscopy of infection of bean by species of Sclerotinia. Mycologia 72:1200-1209.

Madden, L. V., and Hughes, G. 2002. Plant epidemics, models, and analysis. Pages 1557-1562 in: Encyclopedia of Environmetrics, Vol. 3. A. H. El-Shaarawi and W. W. Piegorsch, eds. John Wiley \& Sons, NJ.

Madden, L. V., Hughes, G., and van den Bosch, F. 2007. Study of Plant Disease Epidemics. American Phytopathological Society, St. Paul, MN.

Mahaffee, W. F., and Stoll, R. 2016. The ebb and flow of airborne pathogens: Monitoring and use in disease management decisions. Phytopathology 106: 420-431.

McCullagh, P., and Nelder, J. A. 1989. Generalized Linear Models. Chapman \& Hall, London.

Mila, A. L., Carriquiry, A. L., and Yang, X. B. 2004. Logistic regression modeling of prevalence of soybean Sclerotinia stem rot in the north-central region of the United States. Phytopathology 94:102-110.

Mila, A. L., Yang, X. B., and Carriquiry, A. L. 2003. Bayesian logistic regression of soybean Sclerotinia stem rot prevalence in the U.S. north-central region: Accounting for uncertainty in parameter estimation. Phytopathology 93:758-764.

Mila, A. L., Yang, X. B., Carriquiry, A. L., and Zhao, J. 2001. Modeling the prevalence of soybean Sclerotinia stem rot and the associated economic outcomes in the north central region of USA. Proc. Int. Workshop Plant Epidemiol. 8th. Brazilian Phytopathological Society, Ouro Peeto, Brazil.

Moore, W. D. 1955. Relation of rainfall and temperatures to the incidence of Sclerotinia Sclerotiorum in vegetables in south Florida during the years 1944 to 1954. Plant Dis. Rep. 39:470-472. 
Nutter, F. W., Jr., and Guan, J. 2001. Disease losses. Pages 340-351 in: Encyclopedia of Plant Pathology. O. C. Maloy and T. D. Murray, eds. John Wiley \& Sons, New York.

Oksanen, L. 2001. Logic of experiments in ecology: Is pseudoreplication a pseudoissue? Oikos 94:27-38.

Oksanen, L. 2004. The devil lies in details: Reply to Stuart Hurlbert. Oikos 104:598-605.

Olden, J. D., Lawler, J. J., and Poff, N. L. 2008. Machine learning methods without tears: A primer for ecologists. Q. Rev. Biol. 83:171-193.

Peltier, A. J., Bradley, C. A., Chilvers, M. I., Malvick, D. K., Mueller, D. S., Wise, K. A., and Esker, P. D. 2012. Biology, yield loss and control of Sclerotinia stem rot of soybean. J. Integr. Pest Manage. 3:B1-B7.

Purdy, L. H. 1958. Some factors affecting penetration and infection by Sclerotinia sclerotiorum. Phytopathology 48:605-609.

Purdy, L. H., and Bardin, R. 1953. Mode of infection of tomato plants by the ascospores of Sclerotinia sclerotiorum. Plant Dis. Rep. 37:361-362.

Ripley, B. 2016. Classification and regression trees version 1.0-35. R packages. The Comprehensive R Archive Network (cran). https://cran.r-project. org/web/packages/tree/tree.pdf

Roff, D. A., and Roff, R. J. 2003. Of rats and Maoris: A novel method for the analysis of patterns of extinction in the New Zealand avifauna before European contact. Evol. Ecol. Res. 5:759-779.

Saharan, G. S., and Mehta, N. 2008. Sclerotinia Diseases of Crop Plants: Biology, Ecology and Disease Management. Springer, Dordrecht, The Netherlands.

Savary, S., Teng, P. S., Willocquet, L., and Nutter, F. W., Jr. 2006. Quantification and modeling of crop losses: A review of purposes. Annu. Rev. Phytopathol. 44:89-112.

Schwartz, H. F., and Steadman, J. R. 1978. Factors affecting sclerotium populations of, and apothecium production by, Sclerotinia sclerotiorum. Phytopathology 68:383-388.

Sedun, F. S., and Brown, J. F. 1987. Infection of sunflower leaves by ascospores of Sclerotinia sclerotiorum. Ann. Appl. Biol. 110:275-284.

Sullivan, M. S., Jones, M. J., Lee, D. C., Marsden, S. J., Fielding, A. H., and Young, E. V. 2006. A comparison of predictive methods in extinction risk studies: Contrasts and decision trees. Biodivers. Conserv. 15:19771991.

Sutton, D. C., and Deverall, B. J. 1983. Studies on infection of bean (Phaseolus vulgaris) and soybean (Glycine max) by ascospores of Sclerotinia sclerotiorum. Plant Pathol. 32:251-261.

Tariq, V. N., and Jeffries, P. 1984. Appressorium formation by Sclerotinia sclerotiorum: Scanning electron microscopy. Trans. Br. Mycol. Soc. 82:645651.

Twengström, E., Sigvald, R., Svensson, C., and Yuen, J. 1998. Forecasting Sclerotinia stem rot in spring sown oilseed rape. Crop Prot. 17:405-411.

Van der Plank, J. E. 1963. Plant Diseases: Epidemics and Control. Academic Press, New York.

Wale, S., Platt, H. W., and Cattlin, N. 2008. Fungal and fungal-like diseases. Pages 28-70 in: Diseases, Pests and Disorders of Potatoes: A Colour Handbook. CRC Press, Boca Raton, FL.

Wilson, R. F., ed. 2012. Designing Soybeans for 21st Century Markets. AOCS Press, Urbana, IL.

Workneh, F., and Yang, X. B. 2000. Prevalence of Sclerotinia stem rot of soybeans in the north-central United States in relation to tillage, climate, and latitudinal positions. Phytopathology 90:1375-1382.

Wrather, J. A., and Koenning, S. 2009. Effects of diseases on soybean yields in the United States 1996 to 2007. Online publication. Plant Health Prog. doi.org/10.1094/PHP-2009-0401-01-RS

Wrather, J. A., and Koenning, S. 2014. Estimates of soybean yield reductions caused by diseases in the United States. Online publication. Extension and Outreach, Crop Sciences Department, College of Agricultural, Consumer and Environmental Sciences, University of Illinois, Urbana. http://extension. cropsciences.illinois.edu/fieldcrops/diseases/yield_reductions.php

Wu, B. M., and Subbarao, K. V. 2008. Effects of soil temperature, moisture, and burial depths on carpogenic germination of Sclerotinia sclerotiorum and S. minor. Phytopathology 98:1144-1152.

Yang, X. B., Lundeen, P., and Uphoff, M. D. 1999. Soybean varietal response and yield loss caused by Sclerotinia sclerotiorum. Plant Dis. 83: 456-461. 